\title{
Simultaneous observations at different altitudes of ionospheric backscatter in the eastward electrojet
}

\author{
S. E. Milan, M. Lester \\ Department of Physics and Astronomy, University of Leicester, Leicester, LE1 7RH, UK
}

Received: 25 March 1997 / Revised: 7 July 1997 / Accepted: 8 July 1997

\begin{abstract}
A common feature of evening near-range ionospheric backscatter in the CUTLASS Iceland radar field of view is two parallel, approximately $L$-shellaligned regions of westward flow which are attributed to irregularities in the auroral eastward electrojet region of the ionosphere. These backscatter channels are separated by approximately $100-200 \mathrm{~km}$ in range. The orientation of the CUTLASS Iceland radar beams and the zonally aligned nature of the flow allows an approximate determination of flow angle to be made without the necessity of bistatic measurements. The two flow channels have different azimuthal variations in flow velocity and spectral width. The nearer of the two regions has two distinct spectral signatures. The eastern beams detect spectra with velocities which saturate at or near the ion-acoustic speed, and have low spectral widths (less than $100 \mathrm{~m} \mathrm{~s}^{-1}$ ), while the western beams detect lower velocities and higher spectral widths (above $200 \mathrm{~m} \mathrm{~s}^{-1}$ ). The more distant of the two channels has only one spectral signature with velocities above the ionacoustic speed and high spectral widths. The spectral characteristics of the backscatter are consistent with Eregion scatter in the nearer channel and upper-E-region or F-region scatter in the further channel. Temporal variations in the characteristics of both channels support current theories of E-region turbulent heating and previous observations of velocity-dependent backscatter cross-section. In future, observations of this nature will provide a powerful tool for the investigation of simultaneous E- and F-region irregularity generation under similar (nearly co-located or magnetically conjugate) electric field conditions.
\end{abstract}

Key words. Auroral ionosphere ·

Ionospheric irregularities · Plasma convection

\section{Introduction}

The SuperDARN coherent HF radars (Greenwald et al., 1995) are designed to employ backscatter from highlatitude field-aligned ionospheric plasma density irregularities (radar aurora) as tracers of the bulk plasma motion under the influence of the convection electric field, and hence as a diagnostic tool for the investigation of large-scale magnetospheric-ionospheric coupling. Studies with VHF radars have shown that the Doppler velocity of backscatter arising from E-region irregularities underestimates the plasma drift velocity (e.g. Nielsen and Schlegel, 1983). Hence, HF radars have been developed to exploit F-region irregularities which are generally believed to drift with the background plasma motion (Villain et al., 1985; Ruohoniemi et al., 1987). In addition to plasma flow studies, these radars also allow investigation of the radar aurora themselves and the instability mechanisms which give rise to them. The ability of HF radars to observe backscatter from the $\mathrm{E}$ and $\mathrm{F}$ regions simultaneously will be exploited in this study to compare the characteristics of backscatter originating at different altitudes under similar imposed electric fields. The Co-operative UK Twin Located Auroral Sounding System (CUTLASS) forms the eastern-most pair of radars of SuperDARN, and the Iceland component of this system is the focus of the present study.

Backscatter of the radar sounding wave, $\boldsymbol{k}_{r}$, occurs from ionospheric irregularities with wave vectors, $\boldsymbol{k}$, which satisfy the Bragg condition $\boldsymbol{k}= \pm 2 \boldsymbol{k}_{r}$ (i.e. the irregularity wavelength observed by the radar is half that of the probing radio wave). To a close approximation, the irregularities are field-aligned $(\boldsymbol{k} \perp \boldsymbol{B}$, where $\boldsymbol{B}$ is the magnetic field), requiring that the radar-wave vector be orthogonal to the local magnetic field $\left(\boldsymbol{k}_{r} \perp \boldsymbol{B}\right.$, or the 'magnetic aspect angle,' the angle between $\boldsymbol{k}_{r}$ and the direction perpendicular to $\boldsymbol{B}, \gamma \approx 0^{\circ}$ ) at the point of scatter for coherent backscatter to be observed. The 
advantage of HF radars over VHF radars, which were previously employed for convection studies (e.g. Greenwald et al., 1978; Nielsen et al., 1983), is their ability to achieve the orthogonality condition with the magnetic field over a wide range of altitudes, both in the $\mathrm{F}$ region as well as the $\mathrm{E}$ region, due to the refractive nature of radio-wave propagation in the $3-30-\mathrm{MHz}$ frequency band. Radio waves can be reflected from an ionospheric layer, subsequently returning to the ground at a further range. The ranges at which ground backscatter originating at the point of ground incidence on the down-leg of the radio-wave path - is observed, allow estimates to be made of the ambient ionospheric conditions at the point of reflection, especially when combined with interferometric measurements of the radio-wave elevation angle (Milan et al., 1997a).

Analysis of the autocorrelation function of the returned signals yields backscatter Doppler spectra, from which the spectral characteristics of power, line-ofsight Doppler velocity, $V_{l o s}$, and spectral width, $\Delta V$, can be derived (Hanuise et al., 1993). Ground backscatter has near-zero velocity and low spectral width. The criteria typically applied for distinguishing ground backscatter from ionospheric backscatter are approximately $\left|V_{l o s}\right|<50 \mathrm{~m} \mathrm{~s}^{-1}$ and $\Delta V<20 \mathrm{~m} \mathrm{~s}^{-1}$, although this can be ambiguous in some cases, as such characteristics are not always inconsistent with ionospheric backscatter.

Ionospheric backscatter spectra from the $\mathrm{E}$ region fall into two broad categories, type I and type II, depending on the instability mechanism of the ionospheric irregularity from which the radar signal has been scattered (Fejer and Kelley, 1980; Fejer and Providakes, 1987; Haldoupis, 1989). The dispersion relationship for the instability mechanisms of the $\mathrm{E}$ region is described by the modified two-stream instability theory (Rogister and D'Angelo, 1970; Sudan et al., 1973; Fejer et al., $1975,1984)$ with an oscillatory term

$\omega_{r}=\boldsymbol{k} \cdot \boldsymbol{V}_{d} /(1+\Psi) \equiv k V_{d} \cos \theta /(1+\Psi)$,

and a growth rate given by

$\Gamma=\frac{1}{(1+\Psi)}\left[\frac{\Psi}{v_{i}}\left(\omega_{r}^{2}-k^{2} C_{S}^{2}\right)+\frac{\omega_{r} v_{i}}{k L \Omega_{i}}\right]-2 \alpha n_{0}$.

$\boldsymbol{V}_{d}$ is the differential drift velocity between ions and electrons, $\boldsymbol{V}_{d}=\boldsymbol{V}_{e}-\boldsymbol{V}_{i} ; C_{S}$ is the local ion-acoustic speed,

$C_{S}=\left[K\left(T_{e}+T_{i}\right) /\left\langle m_{i}\right\rangle\right]^{1 / 2}$,

where $T_{i}$ and $T_{e}$ are the ion and electron temperatures and $\left\langle m_{i}\right\rangle$ is the mean ion mass. $C_{S}$ typically takes a value of $350-400 \mathrm{~m} \mathrm{~s}^{-1}$ at an altitude of $110 \mathrm{~km} . \Psi=v_{e} v_{i} /$ $\Omega_{e} \Omega_{i}$ for field-aligned irregularities (for which the magnetic aspect angle $\gamma=0^{\circ}$ ), where $v_{i}, v_{e}, \Omega_{i}$ and $\Omega_{e}$ are the ion and electron collision and gyro frequencies. At E-region altitudes $\Psi \ll 1 ; n_{0}$ is the background electron density and $L$ is a measure of the scale length of gradients in $n_{0}$ parallel to $\boldsymbol{E}$ and perpendicular to $\boldsymbol{B} ; \alpha$ is the recombination rate. The 'flow angle', $\theta=$ $\cos ^{-1}\left(\boldsymbol{k} \cdot \boldsymbol{V}_{d} / k V_{d}\right)$, is the angle between the electron drift velocity and the irregularity wave vector, which is also, necessarily, the angle between the probing radio wave and the drift velocity. Hence, the radar line-of-sight component of the drift velocity is $V_{d} \cos \theta$. The first and second terms in $\Gamma$ are the two-stream and gradient drift growth terms, respectively, and the third term is due to recombinational damping.

At E-region altitudes, between about 100 and $115 \mathrm{~km}$, the ion-neutral collision frequency is sufficiently high $\left(v_{i} \gg \Omega_{i}\right)$ to constrain the ion population to the neutral flow speed (which we assume to be negligibly small), whereas the electrons move under the influence of the convection electric field, $\boldsymbol{V}_{\boldsymbol{E} \times \boldsymbol{B}}=\boldsymbol{E} \times \boldsymbol{B} / B^{2}$, giving a differential drift velocity $\boldsymbol{V}_{d} \cong \boldsymbol{V}_{\boldsymbol{E} \times \boldsymbol{B} \text {. }}$.

In the absence of electron density gradients $(L \rightarrow \infty)$ the dispersion relationship reduces to the two-stream (or Farley-Buneman) instability (Farley, 1963; Buneman, 1963), generated by the differential flow between ions and electrons. The irregularities produced by the twostream instability are observed in radar backscatter as type-I Doppler spectra. From the marginal instability condition $\Gamma=0$, it can be shown that the two-stream instability requires $V_{d} \cos \theta>C_{S}(1+\Psi)$ (essentially $V_{d} \cos \theta>C_{S}$ ) to be generated (Sudan, 1983). Hence, there is a 'cone of instability' in which type-I spectra can be observed. Within the cone of instability, observations show that the type-I spectra have a Doppler velocity constrained to be near the local ion-acoustic speed, $V_{\text {los }} \approx C_{S} \quad\left(\omega_{r}=k C_{S}\right), \quad$ even in situations where $V_{d} \cos \theta>C_{S}$ (Nielsen and Schlegel, 1983). For high electron flow speeds, $C_{S}$ (and hence the Doppler velocity of type-I spectra) can increase as a consequence of enhanced $T_{e}$ (Robinson, 1986) by turbulent heating of the electrons through a combination of long-wavelength gradient drift waves and an anomalous collision frequency (Primdahl and Bahnsen, 1985; Robinson, 1986). Hence $C_{S}$ is related in an indirect way to the convection electric field. In general, however, $C_{S}$ remains an underestimate of the true drift speed, $\boldsymbol{V}_{\boldsymbol{E} \times \boldsymbol{B}}$, in the E region. This is an important consideration for convection studies, producing inaccuracy not only in flowspeed estimates, but also flow direction in the case of bistatic merged vector velocities (Robinson, 1993). Type-I spectra generally have a low spectral width.

In the presence of a suitably destablising electron density gradient $\left(L>0 \mathrm{~m}\right.$ and finite), the threshold $V_{d}$ for instability decreases (Fejer et al., 1984), as a consequence of a second plasma instability, the gradient drift instability (Maeda et al., 1963; Knox, 1964). The electron density gradients produced by the modulation of the plasma density $\left(\delta n / n_{0}\right)$ by 'primary' twostream irregularities provide an ideal environment for the generation of 'secondary' gradient drift waves (Sudan et al., 1973), in which case they have a drift velocity

$V_{d s}=\frac{v_{i}}{\Omega_{i}} \frac{V_{d}}{(1+\Psi)} \frac{\delta n}{n_{0}}$,

with a direction of propagation close to perpendicular to the plasma flow. Gradient drift irregularities produce type-II Doppler spectra in radar backscatter, which are 
broader than type-I spectra, with velocities below the ion-acoustic speed.

Under extremely turbulent conditions, it is thought that irregularities with non-zero aspect angles $\left(\gamma>0^{\circ}\right)$, can be generated, though generally with aspect angles smaller than a fraction of a degree (e.g. Haldoupis, 1989). Such non-field-aligned irregularities are predicted to have a phase velocity lower than that of field-aligned irregularities (Fejer and Kelley, 1980), and this mechanism has been proposed as an explanation for the observation of low-velocity two-stream and gradient drift irregularities (Kustov et al., 1994).

Observations by Villain et al. (1987) indicate that, in the presence of significant field-parallel electron drifts (field-aligned currents), the ion-acoustic instability and electrostatic $\mathrm{NO}^{+}$ion cyclotron instability $\left(\omega_{r}^{2}=\right.$ $\left.\Omega_{i}^{2}+k^{2} C_{S}^{2}\right)$ can be generated in the upper $\mathrm{E}$ region by sub-critical field-perpendicular drifts, as predicted by Chaturvedi et al. (1987). These instabilities will produce irregularities with phase velocities higher than the background plasma drift speed, $\boldsymbol{V}_{\boldsymbol{E} \times \boldsymbol{B}}$, though which saturate within their cones of instability, and hence display no flow-angle variation.

At higher altitudes, above $130 \mathrm{~km}$, ion magnetisation becomes significant as $\Omega_{i} \gg v_{i}$, and the relative drift between ions and electrons decreases and changes direction, $\boldsymbol{V}_{d} \cong-\left(v_{i} / \Omega_{i}\right) \boldsymbol{E} / B$. In this case very large electric fields are necessary to generate the two-stream instability, and other (not fully understood) instability processes dominate. Such high-altitude, or 'F-region', irregularities are thought to be generated in electron density gradients, in much the same way as by the gradient drift instability (Fejer et al., 1984), with possible contributions from field-aligned currents, by a mechanism known as the current convective instability (Ossakow and Chaturvedi, 1979). Kelley et al. (1982) discuss the production of $50-\mathrm{km}$-scale irregularities in the auroral F region by soft precipitation. Such structures provide steep electron density gradients in which smaller-scale irregularities can grow. Previous studies indicate that F-region irregularities observed by $\mathrm{HF}$ radars propagate with the plasma drift speed, $\boldsymbol{V}_{\boldsymbol{E} \times \boldsymbol{B}}$, and are not velocity limited (Villain et al., 1985; Ruohoniemi et al., 1987), making them suitable tracers of the plasma flow.

The present study describes a backscatter feature which is often observed within the pre-midnight auroral electrojet region by the CUTLASS Iceland radar. Three different backscatter spectral types are distinguished, type I and type II from E-region altitudes, together with a third which has a broad and often multi-peaked spectral shape and which is thought to originate at higher altitudes, in the upper $\mathrm{E}$ region or $\mathrm{F}$ region. The nature of the backscatter feature allows simultaneous observation of irregularities over a range of flow angles and altitudes, providing a powerful technique for the investigation of both E- and F-region instability mechanisms. To the authors' knowledge this is the first time that simultaneous measurements of irregularities at different altitudes in the $E$ and $F$ regions by the same instrument over a large range of flow angles have been possible.

\section{The CUTLASS coherent HF radars}

The CUTLASS radars are located at Hankasalmi $\left(62.3^{\circ} \mathrm{N}, 26.6^{\circ} \mathrm{E}\right)$ in Finland and Pykkvibær $\left(63.8^{\circ} \mathrm{N}\right.$, $20.5^{\circ} \mathrm{W}$ ) in Iceland (Fig. 1). Each of the two radars comprises two arrays of log-periodic antennas, a main array of 16 antennas with both transmit and receive capability, and an interferometer array of four antennas with receive capability only. The radars can operate in the HF band between 8 and $20 \mathrm{MHz}$. The observations made in the present study were made at a radar operating frequency of approximately $10 \mathrm{MHz}$ (corresponding to an irregularity wavelength of $15 \mathrm{~m}$ ). The antennas in each array are phased with respect to one another to form an antenna pattern in which the maximum gain (beam position) has one of 16 azimuthal pointing directions (azimuth $\phi$ ) separated by approximately $3.2^{\circ}$, distributed symmetrically about the radar boresites of $-12^{\circ}$ (i.e. west of north) and $30^{\circ}$ (east of north) for the Finland and Iceland radars, respectively. In the normal scan mode of the radars, the 16 beams are sounded with a dwell time of $7 \mathrm{~s}$, producing field-of-view maps of backscatter, with an azimuthal coverage of over $50^{\circ}$, every $2 \mathrm{~min}$. Typically, 75 range gates are sampled for each beam, with a pulse length of $300 \mu$ s, corresponding to a gate length of $45 \mathrm{~km}$, and a lag to the first gate of $1200 \mu \mathrm{s}(180 \mathrm{~km})$. In this configuration the maximum range of the radars is approximately $3550 \mathrm{~km}$, with each field of view containing 1200 cells.

A 7-pulse scheme is transmitted, allowing the power and spectral width of the backscatter to be estimated by a functional fit to the decorrelation of the autocorrelation function at each range gate. Line-of-sight Doppler velocity is determined by a least-squares fit to the phase

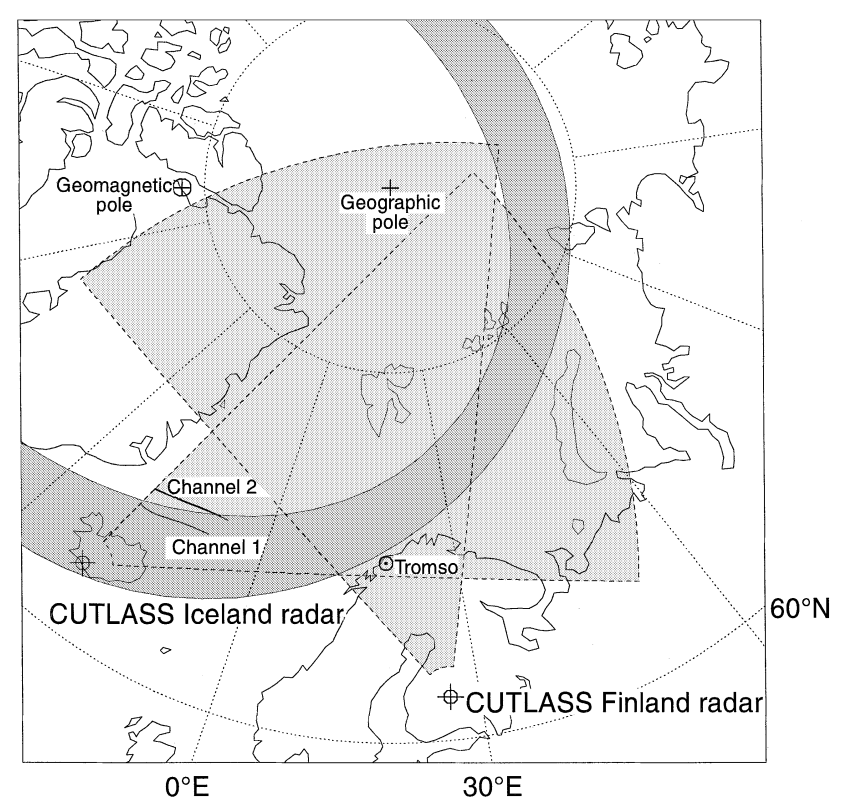

Fig. 1. The location of the fields of view of the CUTLASS Finland and Iceland radars. Also indicated is the location of the $K_{p}=0$ auroral oval at 22 UT (Feldstein and Starkov, 1967; Holzworth and Meng, 1975) 
of the complex value of the ACF as a function of lag. The elevation angle of backscatter can be determined from an interferometric analysis of the return backscatter, a phase difference being determined from the crosscorrelation function of the signals received at the main and interferometer arrays [described more fully in Milan et al. (1997a)].

\section{Observations}

A common feature of the observations of the Iceland radar between 18 and 01 UT (18-01 MLT) is near-range ionospheric and ground backscatter. In general, the ionospheric backscatter appears between range gates 0 and 20 (approximately radar ranges below $1000 \mathrm{~km}$ ) and the ground backscatter appears between range gates 20 and 40. The geomagnetic latitude (GMLAT) range over which this ionospheric backscatter is observed is approximately $66^{\circ}$ to $74^{\circ}$ GMLAT [in the altitude adjusted corrected geomagnetic (AACGM) coordinate system, based on Baker and Wing (1989)]. Two typical examples of this backscatter feature are illustrated in Fig. 2 in which backscatter power, line-of-sight velocity and spectral width are plotted as a function of beam and range gate for one radar scan, from 0000 UT, 3 January 1997 and 2054 UT, 2 January 1997.

In the first example (upper three panels), a region of backscatter is observed between range gates 6 to 11 on the left-hand edge of the field-of-view (beam 0), extending to between range gates 12 and 21 in beam 10. Within this region of backscatter there are two maxima in the power, apparently describing two parallel 'channels' (indicated by the black/white dashed lines). The line-ofsight velocities measured in this region of backscatter also demarcate into these two channels. The channel at nearer ranges (hereafter referred to as channel 1) contains velocities between 0 and $300 \mathrm{~m} \mathrm{~s}^{-1}$, and the channel at further ranges (channel 2) contains velocities between 700 and $2300 \mathrm{~m} \mathrm{~s}^{-1}$ (though the velocity scale indicated saturates at $900 \mathrm{~m} \mathrm{~s}^{-1}$ ). In both channels the line-of-sight velocities are towards the radar. In the spectral width data, two regions of ionospheric backscatter are again apparent, channel 1 having low spectral widths, in general below $150 \mathrm{~m} \mathrm{~s}^{-1}$, and channel 2 having high spectral widths, in general above $300 \mathrm{~m} \mathrm{~s}^{-1}$. The two channels, when mapped into a geomagnetic coordinate system, are found to be approximately aligned in a zonal direction. They have been represented in Fig. 1 by two lines in the Iceland field of view.

At ranges beyond channel 2 there is a region of backscatter - attributed to ground backscatter - which is approximately parallel to the two channels of the ionospheric backscatter. The range at which the ground backscatter is observed is generally twice the range to the ionospheric backscatter of channel 1. It must be noted that there is a portion of the field of view - beams 6 to 8 and between range gates 25 and 31 - in which little ground backscatter is observed. This 'null' in the field of view, the cause of which is thought to be sea ice with a low backscatter cross-section (Shand et al., 1997), is apparent in both examples of Fig. 2. Ionospheric backscatter observed at the nearest ranges of the field of view, range gates 0 to 5 , is thought to be associated with meteor scatter (e.g. Hall et al., 1997) and will not be considered any further in this study.

The second example of Fig. 2 (lower 3 panels) is very similar to the first, except for the presence of additional regions of backscatter, somewhat obscuring the pattern just described. However, it is still possible to discern the two zonally aligned ionospheric backscatter channels and a parallel region of ground backscatter at further ranges. It is possible, in this instance, that a second region of ground scatter is present at twice the range of the channel 2 backscatter region, between range gates 32 and 42 in beams 5 to 12 .

The locations of the regions of backscatter which are of interest to the present study are summarised in the schematic presented in Fig. 3 (see Sect. 4.3 for a description of the annotation). Also, the locations of the centres of the ionospheric backscatter channels for 2054 UT, 2 January 1997 are indicated in Fig. 1.

The feature just described is observed predominantly during the months November to January. Near-range backscatter was observed by the CUTLASS Iceland radar on $97 \%$ of nights during the interval October 1996 to February 1997. During nights when near-range scatter was observed, the two channel backscatter feature was present on $17 \%, 63 \%, 59 \%, 59 \%$ and $31 \%$ of nights in the months October 1996 to February 1997, respectively. In other months of the year, the feature is rarely observed.

\section{Discussion}

The local time extent, latitude and zonally aligned nature of the ionospheric backscatter is consistent with the expected location of the eastward electrojet, previously observed in VHF radar studies (Greenwald et al., 1973, 1975; Tsunoda et al., 1976) which have shown the co-location of the electrojet region and radar aurora. In this region of the ionosphere, the convection electric field $\boldsymbol{E}$ is directed meridionally polewards and the magnetic field $\boldsymbol{B}$ is essentially vertical, resulting in $\boldsymbol{E} \times \boldsymbol{B}$ plasma flow which is approximately zonal and westward. The zonal flow assumption allows an estimation of flow angles and irregularity drift speeds to be made and hence makes possible the investigation of the instability mechanisms giving rise to backscatter. In the following discussion it is assumed that the convection electric field in both channels 1 and 2 is similar (the two channels are nearly co-located) and that the different line-of-sight velocity behaviours observed in the two channels are not a consequence of differing plasma flow regimes. This assumption is supported by the frequent observation of the two backscatter channels in the same location over a range of geomagnetic activity levels. 


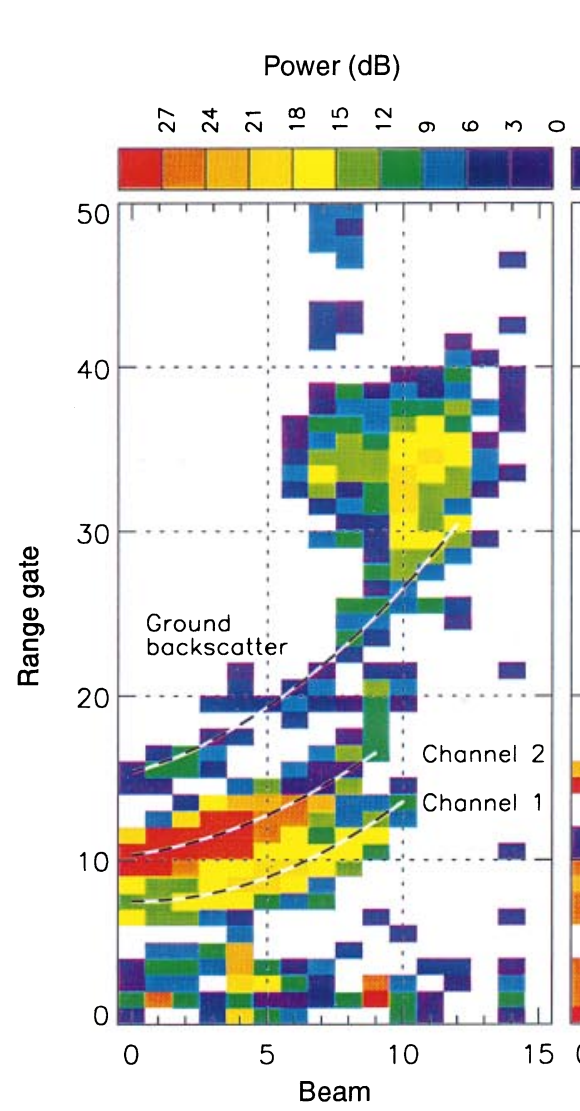

Power (dB)
0000 UT 3 January 1997

Velocity $\left(\mathrm{m} \mathrm{s}^{-1}\right)$
Width $\left(\mathrm{m} \mathrm{s}^{-1}\right)$

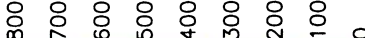

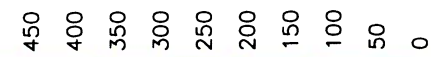
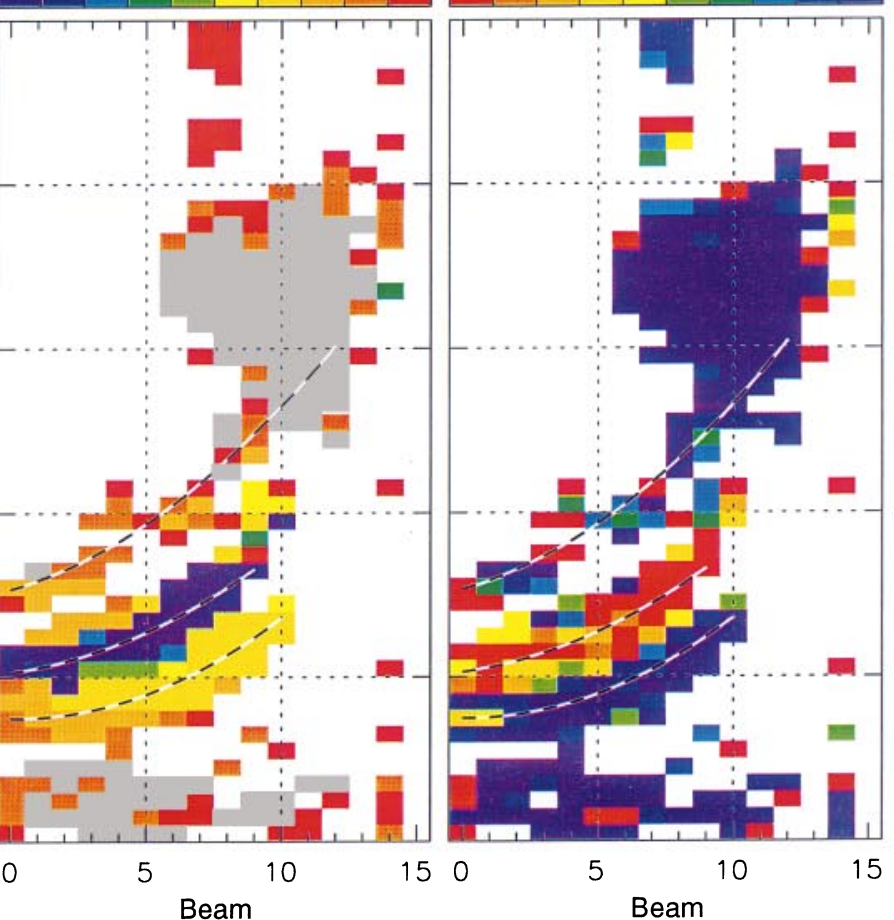

2054 UT 2 January 1997

Velocity $\left(\mathrm{m} \mathrm{s}^{-1}\right)$

Width $\left(\mathrm{m} \mathrm{s}^{-1}\right)$

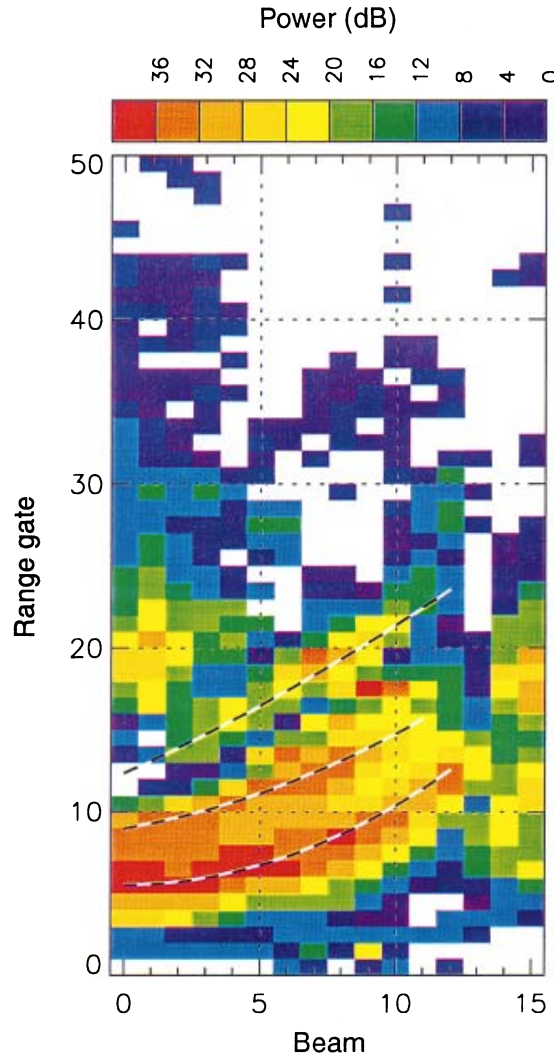

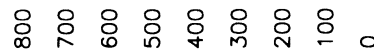

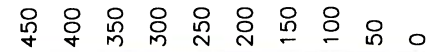
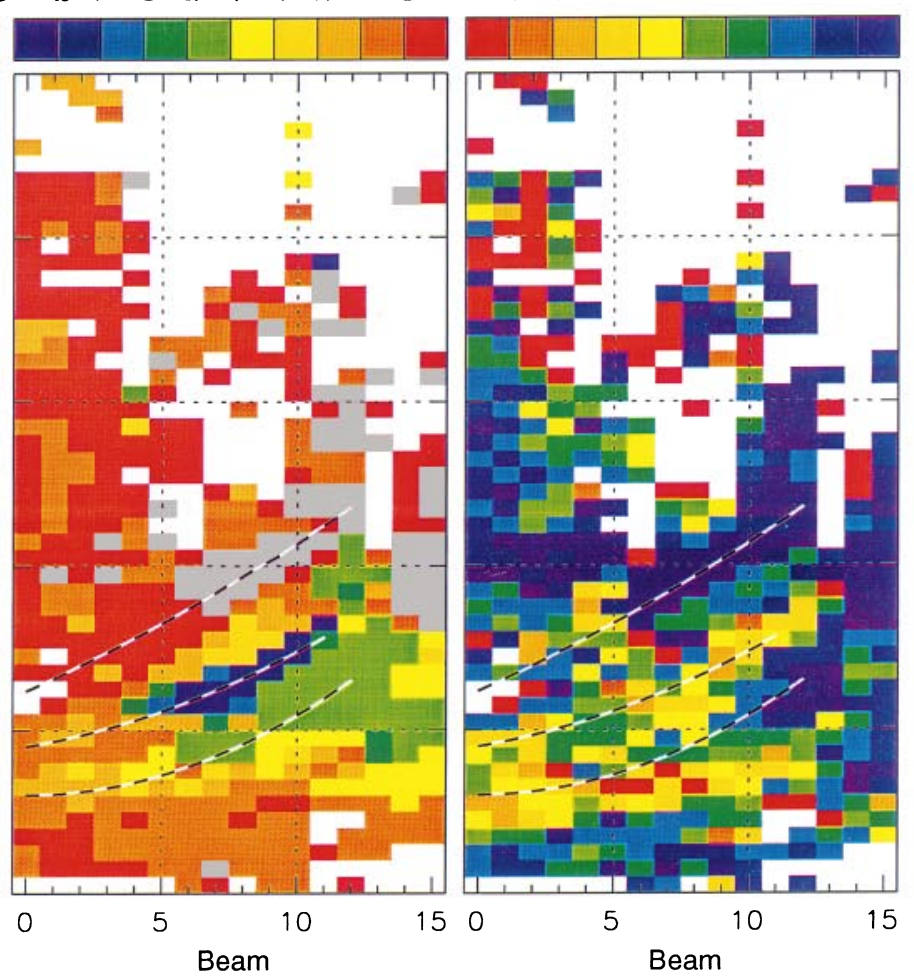

Fig. 2. The backscatter power, line-of-sight velocity and spectral width in the CUTLASS Iceland radar field of view at 0000 UT, 3 January 1997 and 2054 UT, 2 January 1997 


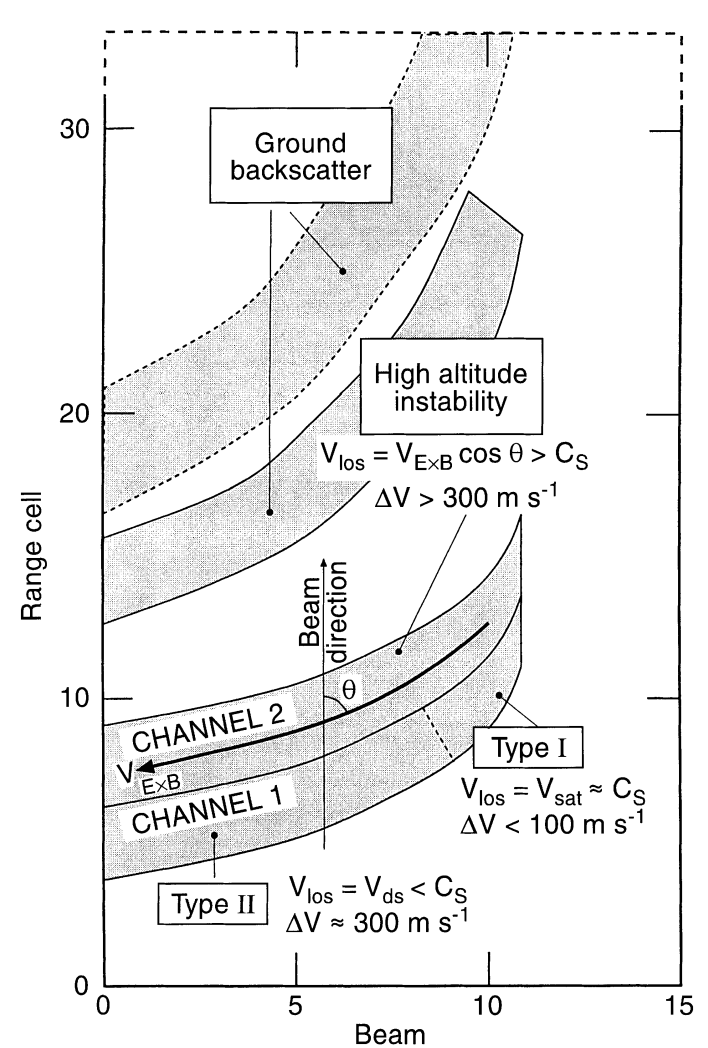

Fig. 3. A schematic diagram illustrating the typical locations of the channel 1 and 2 backscatter regions in the CUTLASS Iceland radar field of view, observed in the eastward electrojet region. Also indicated are the locations of ground backscatter regions associated with the ionospheric scatter; the ground backscatter at further ranges (dotted outline) is sometimes not observed. The instability mechanisms and line-of-sight velocities associated with the channel 1 and 2 backscatter are discussed in the text

\subsection{Determination of the direction of flow across the field of view}

The backscatter feature investigated in this study generally appears at ranges within the CUTLASS Iceland field of view which are outside the common volume of the bistatic CUTLASS radar system (see Fig. 1). Consequently, merged vector velocities cannot be determined, and assumptions have to be made concerning the direction of flow within the feature if true plasma drift speeds are to be estimated. Three schemes for the estimation of flow angle (the angle between the radar beam and the plasma flow direction) will be presented, each based on the general assumption that flow within the electrojet region is essentially zonal. In all three schemes, the radar beams at the left of the field of view are close to perpendicular to the zonal plasma flow direction and hence the flow angle $\theta \approx 90^{\circ}$; towards the right of the field of view this flow angle decreases.

In the first scheme (i) the plasma flow is assumed to be aligned along the backscatter channels observed by the radar. A consideration of the power and velocity profiles along each radar beam allows the range to the centre of each backscatter channel to be determined.
Such a determination is illustrated by the solid and dotted curves in Fig. 4a for the first example of Fig. 2. The dashed lines in this panel indicate a second-order polynomial least-squares fit (coefficients $r_{0}, r_{1}$ and $r_{2}$ ) to the range, $r$, as a function of beam, or radar azimuth $\phi$ (measured from beam 0), of the form

$r(\phi)=r_{2} \phi^{2}+r_{1} \phi+r_{0}$

and hence

$\mathrm{d} r(\phi) / \mathrm{d} \phi=2 r_{2} \phi+r_{1}$.

The flow angle, $\theta$, is then found to be given by

$\tan (\theta+\phi)=\frac{(\mathrm{d} r / \mathrm{d} \phi) \sin \phi+r \cos \phi}{(\mathrm{d} r / \mathrm{d} \phi) \cos \phi-r \sin \phi}$,

which is illustrated in Fig. $4 \mathrm{~b}$ for both channels 1 and 2 (solid and dotted lines labelled i). This determination of $\theta$ is very sensitive to the choice of range gates along a channel, and large error bars $\left( \pm 10^{\circ}\right)$ have to be assumed, especially for high $\theta$.

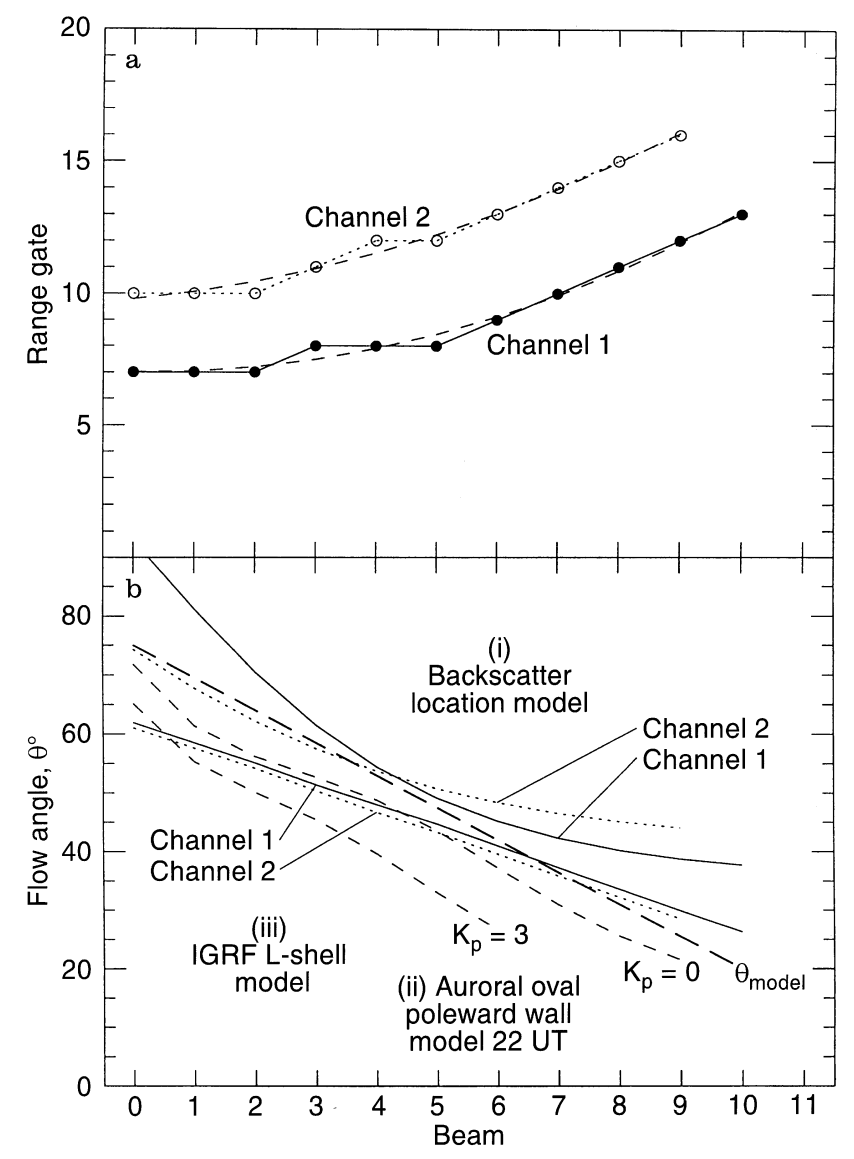

Fig. 4. a The location within the field of view of centre of the channel 1 and 2 backscatter regions (solid and dotted lines, respectively) and least-squares fits to these curves (dashed lines). b The flow angle, $\theta$, determined from the locations of the backscatter channels (solid and dotted lines), determined from the location of the poleward wall of the auroral oval (dashed lines), and determined from the geomagnetic azimuth along the channels (dot-dashed lines). The model variation of flow angle, $\theta_{\text {model }}$, assumed for the present study is also indicated (thick dashed line) 
The second scheme (ii) assumes that flow is parallel to the poleward wall of the auroral oval, as this appears to be approximately co-located with the backscatter channels (see Fig. 1) and is assumed to be parallel to the convection reversal boundary. In a similar manner to scheme (i), the flow angle is determined from a fourthorder polynomial fit to the range along each beam to the poleward wall of the auroral oval, based on the model of Feldstein and Starkov (1967) and Holzworth and Meng (1975). The flow angle determined in this way is illustrated in Fig. 4b for $K_{p}=0$ and $K_{p}=3$ at 22 UT (dashed lines labelled ii).

Finally, in the third scheme (iii), the flow is assumed to be exactly $L$-shell aligned. The variation in angle between the radar beam and the line of constant $L$ along the backscatter channels is determined from the IGRF geomagnetic field model and is also illustrated in Fig. 4b (solid and dotted lines labelled iii).

All three schemes indicate that the flow angle is high (low) to the left (right) of the field of view, though the exact values of $\theta$ vary somewhat for each channel or value of $K_{p}$. An exact determination of $\theta$ is clearly impossible. In consequence, an approximate variation of flow angle across the field of view has been adopted in the rest of the study (illustrated in Fig. 4b, thick dashed line labelled $\theta_{\text {model }}$ ) which decreases linearly from $75^{\circ}$ at the left of the field of view to $20^{\circ}$ at the eastern-most extent of the backscatter.

\subsection{Flow-angle dependence of irregularity drift velocity and spectral width}

Despite the difficulties in determining the exact variation in flow angle across the field of view, even an approximate estimate allows the flow-angle dependence of the backscatter characteristics observed along channels 1 and 2 to be investigated. To this end, plotted in Fig. $5 \mathrm{a}$ are the backscatter power, line-of-sight velocity and spectral width as measured by the radar along the centre of both backscatter channels, for the first example of Fig. 2, 0000 UT, 3 January 1997. The velocity along channel 2 increases from values of $700 \mathrm{~m} \mathrm{~s}^{-1}$ at the left of the field of view (beam 0) to values of $2300 \mathrm{~m} \mathrm{~s}^{-1}$ in beam 9. If the flow velocity is approximately uniform along the zonal flow direction, this line-of-sight velocity variation (and the variation of $\theta_{\text {model }}$ ) across the field of view are consistent with a value of $\boldsymbol{V}_{\boldsymbol{E} \times \boldsymbol{B}} \approx 3000 \mathrm{~m} \mathrm{~s}^{-1}$ (the variation of $V_{\text {los }}=\boldsymbol{V}_{\boldsymbol{E} \times \boldsymbol{B}} \cos \theta_{\text {model }}$ for $\boldsymbol{V}_{\boldsymbol{E} \times \boldsymbol{B}}=3000 \mathrm{~m} \mathrm{~s}^{-1}$ is indicated by a dashed line). The velocity in channel 1 begins to increase from $100 \mathrm{~m} \mathrm{~s}^{-1}$ in beam $0\left(\theta \approx 70^{\circ}\right)$ to $250 \mathrm{~m} \mathrm{~s}^{-1}$ in beam $3\left(\theta \approx 60^{\circ}\right)$. However, the velocity saturates at approximately $250 \mathrm{~m} \mathrm{~s}^{-1}$ and does not increase for $\theta \lesssim 60^{\circ}$. The spectral width variation with flow angle is also different for channels 1 and 2. In channel $1, \Delta V$ has values of $300 \mathrm{~m} \mathrm{~s}^{-1}$ for high $\theta$ but falls to very low values; $100 \mathrm{~m} \mathrm{~s}^{-1}$ and less, near the point at which the channel 1 line-of-sight velocity saturates at $250 \mathrm{~m} \mathrm{~s}^{-1}$. Spectral widths along channel 2 are high for all $\theta$, varying in an apparently random manner between 300 and $1100 \mathrm{~m} \mathrm{~s}^{-1}$.
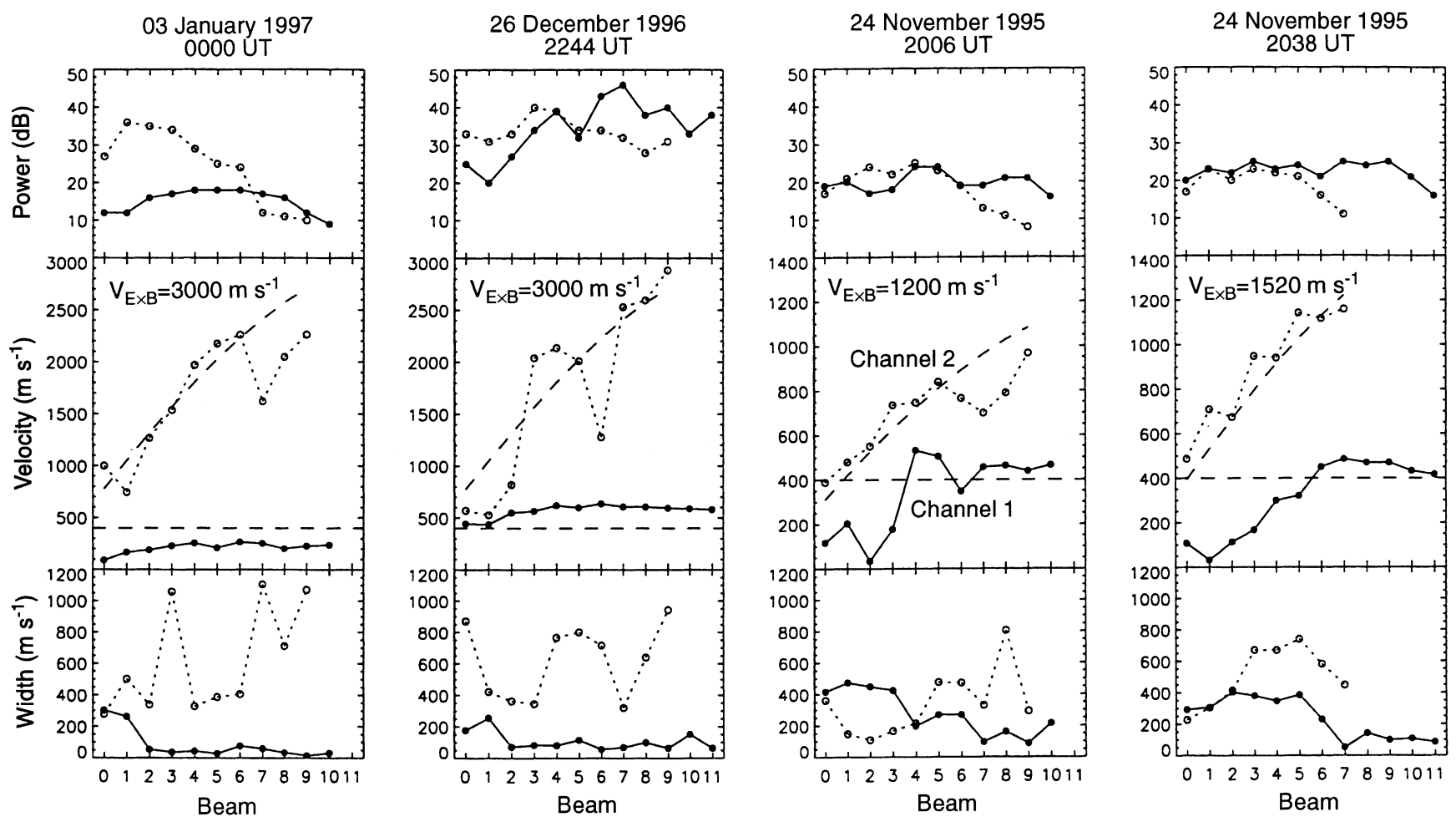

Fig. 5a-d. The backscatter power, line-of- sight velocity and spectral width observed along channel 1 (solid lines) and channel 2 (dotted lines) at a 0000 UT, 3 January 1997, b 2244 UT, 2 January 1997, c 2006 UT, 24 November 1995 and d 2038 UT, 24 November 1995. To aid comparison, a horizontal dashed line is marked at $400 \mathrm{~m} \mathrm{~s}^{-1}$ in the velocity panels 
A second example in which very high plasma flow speeds are observed is illustrated in Fig. 5b, for 2244 UT, 26 December 1996. Again, the velocity along channel 2 increases with decreasing flow angle, consistent with $\boldsymbol{V}_{\boldsymbol{E} \times \boldsymbol{B}} \approx 3000 \mathrm{~m} \mathrm{~s}^{-1}$. The channel 1 velocity varies approximately from $400 \mathrm{~m} \mathrm{~s}^{-1}$ in beam 0 to $600 \mathrm{~m} \mathrm{~s}^{-1}$ near beam 3 , at which value it saturates for $\theta \lesssim 60^{\circ}$. The spectral widths also follow the variation described for the first example. The major difference between these two examples is the value at which the channel 1 velocity saturates, $V_{\text {sat }} \approx 250$ and $600 \mathrm{~m} \mathrm{~s}^{-1}$, respectively.

Parts c and d of Fig. 5 illustrate two examples (2006 and $2038 \mathrm{UT}$ ) from the interval 1915 to $2045 \mathrm{UT}, 24$ November 1995, during which the electrojet backscatter feature was observed almost continuously for $1.5 \mathrm{~h}$. During this interval, the observed values of $\boldsymbol{V}_{\boldsymbol{E} \times \boldsymbol{B}}$ were lower than for the examples already presented, between approximately 700 and $1500 \mathrm{~m} \mathrm{~s}^{-1}$. Despite the lower channel 2 velocities, both examples follow the pattern described. The channel 1 velocities saturate near
$500 \mathrm{~m} \mathrm{~s}^{-1}$ at the same values of $\theta$ at which their respective channel 1 spectral widths fall from values near $400 \mathrm{~m} \mathrm{~s}^{-1}$ to values below $200 \mathrm{~m} \mathrm{~s}^{-1}$, in beams 4 and 6 at 2006 and 2038 UT, respectively.

A comparison of the backscatter Doppler spectra observed in channels 1 and 2 for 0000 UT, 3 January 1997 (Fig. 5a) and 2038 UT, 24 November 1995 (Fig. 5d) are illustrated in Fig. 6. The spectra observed in channel 1 have a single, narrow peak. The backscatter observed in channel 2 has broader - and often multipeaked - spectra, especially for the high $\boldsymbol{V}_{\boldsymbol{E} \times \boldsymbol{B}}$ case of 3 January. It is possible in this example, especially in beams $0,2,3$ and 4 , that the channel 2 backscatter spectra contain a low-velocity peak corresponding to the single peak observed in the channel 1 spectra. The multipeaked nature of the channel 2 backscatter spectra explain the more random variation in velocity and spectral width in the channel 2 measurements than in the channel 1 measurements. In the case of single-peaked spectra (24 November 1995, Fig. 6) a very good fit of the line-of-sight velocities to $\boldsymbol{V}_{\boldsymbol{E} \times \boldsymbol{B}} \cos \theta$ is found (Fig. 5d).
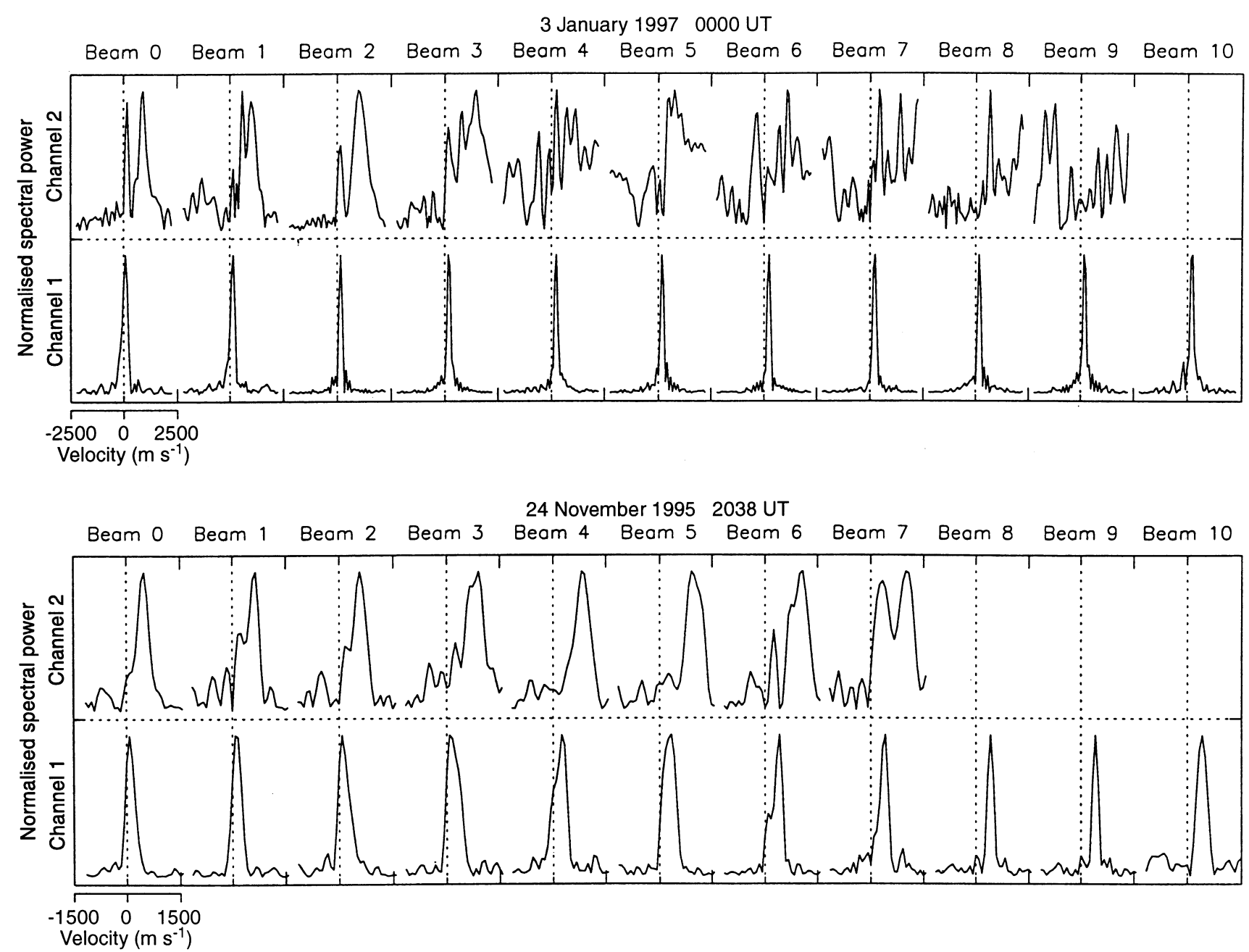

Fig. 6. A comparison of Doppler spectra observed along channels 1 and 2 at 0000 UT, 3 January 1997 and 2038 UT, 24 November 1995 (corresponding to a and d of Fig. 5). Note the differing velocity scales for the two examples 


\subsection{Instability mechanisms}

Channels 1 and 2 have backscatter characteristics which respond very differently to the same (or similar) convection electric field, though their centre lines are separated by never more than $200 \mathrm{~km}$. Channel 1 has low velocities at high flow angles, and velocities which saturate at between 250 and $700 \mathrm{~m} \mathrm{~s}^{-1}$ for low flow angles. The spectral width of channel 1 backscatter is approximately 100 and $300 \mathrm{~m} \mathrm{~s}^{-1}$ in the saturated and unsaturated line-of-sight velocity regimes, respectively. Channel 2 has, in general, line-of-sight velocities which appear to obey the $\cos \theta$ rule at all flow angles.

A possible interpretation of these results is of different instability mechanisms operating in the two channels, producing different types of irregularity backscatter. Type-I spectra, generated by the two-stream instability, have low spectral widths and Doppler velocities near the local ion-acoustic speed, and it is possible that this is the saturation velocity in channel 1 . At high flow angles the radar beam is no longer within the cone of instability, $V_{d} \cos \theta<C_{S}$, and type-I spectra are no longer observed. At these lower line-of-sight velocities, the gradient drift instability dominates, producing broader type-II Doppler spectra with velocities below the ion-acoustic speed, consistent with the backscatter characteristics of the channel 1 unsaturated velocity regime. The channel 1 spectral shapes illustrated in Fig. 6 are consistent with this identification of type-I and type-II backscatter. In the unsaturated velocity regime (beams 0 to 1 for 3 January 1997 and beams 0 to 6 for 24 November 1995) the spectra straddle the zero velocity point of the spectrum, whereas in the saturated velocity regime the spectra all lie in the positive velocity range of the spectrum, characteristics of type-II and type-I spectra, respectively (Haldoupis, 1989).

The backscatter characteristics within channel 2 are more difficult to interpret. That velocities are observed which are much higher than the saturated velocities of channel 1 suggests either the ion-acoustic speed within the scatter volume is enhanced, or it is no longer a limiting factor. Auroral-E-region type-IV spectra have been observed with low spectral widths (similar to type-I spectra) but with velocities far in excess of the usual ionacoustic speed (e.g. Providakes et al., 1985). Such spectra are thought to occur when the irregularities are generated by the two-stream instability operating in regions where $C_{S}$ is considerably enhanced by turbulent heating of the ionosphere (Primdahl and Bahnsen, 1985; Robinson, 1986). Under ambient conditions the ion and electron temperatures, $T_{i}$ and $T_{e}$, at $110 \mathrm{~km}$ are approximately equal to $300 \mathrm{~K}$. Under turbulent heating conditions, $T_{e}$ increases but $T_{i}$ remains unchanged. As $C_{S} \propto\left(T_{i}+T_{e}\right)^{1 / 2}$, an increase in $T_{e}$ to $2000 \mathrm{~K}$, possible under the influence of electric fields of $100 \mathrm{mV} \mathrm{m}^{-1}$ (flow velocities of $2000 \mathrm{~m} \mathrm{~s}^{-1}$ ) (Davies and Robinson, 1997), raises $C_{S}$ by a factor of 2 to approximately $800 \mathrm{~m} \mathrm{~s}^{-1}$. This, however, is clearly insufficient to explain the $2500-\mathrm{m} \mathrm{s}^{-1}$ velocities observed by the radar.

Another interpretation is that these irregularities are generated by the ion-acoustic or electrostatic ion cyclo- tron instabilities operating in the presence of significant field-aligned currents, with phase velocities higher than the (subcritical) background plasma drift velocity (Villain et al., 1987). That field-aligned currents are present in the vicinity of the backscatter channels is suggested by the observation of a ground backscatter region (see Sect. 4.5). However, such irregularities would be expected to display a phase velocity independent of flow angle, in much the same way as two-stream irregularities, which is not consistent with the $\cos \theta$ behaviour observed in channel 2 .

Alternatively, if the channel 2 backscatter originates from the upper $\mathrm{E}$ region or $\mathrm{F}$ region, where the ions become magnetised $\left(v_{i} \ll \Omega_{i}\right), V_{d}$ (the differential flow between ions and electrons) decreases for a given $\boldsymbol{V}_{\boldsymbol{E} \times \boldsymbol{B}}$ and the line-of-sight Doppler velocity is no longer limited by $C_{S}$. In this case, the velocity measured by the radar should be a true indication of the line-of-sight component of the plasma drift velocity $\boldsymbol{V}_{\boldsymbol{E} \times \boldsymbol{B}}$ (Villain et al., 1985; Ruohoniemi et al., 1987). It is interesting to note that at flow angles outside the cone of instability of the two-stream instability (i.e. in the region that gradient drift waves are observed in channel 1) the line-of-sight velocity measured in channel 1 is, in general, lower than the velocity measured in channel 2 . If it is assumed that the electric field experienced by channels 1 and 2 is similar, this contradicts findings that type-II Doppler velocities are in good agreement with $\boldsymbol{V}_{\boldsymbol{E} \times \boldsymbol{B}}$ (Ecklund et al., 1977; Cahill et al., 1978). A more rigorous flow-angle analysis is necessary to determine whether this is a geometrical effect. Alternatively, if it is assumed that these spectra are produced by secondary gradient drift waves (with phase velocity $V_{d s}$ ) generated within background primary two-stream waves (with phase velocity $V_{d}=\boldsymbol{V}_{\boldsymbol{E} \times \boldsymbol{B}}>C_{S}$ and turbulence level $\left.\delta n / n_{0}\right)$, then the difference between $\boldsymbol{V}_{\boldsymbol{E} \times \boldsymbol{B}}$ and $V_{d s}$ can give an estimate of $\delta n / n_{0}$ : substituting $\boldsymbol{V}_{\boldsymbol{E} \times \boldsymbol{B}}$ for $V_{d}$ into the relationship for the drift speed of secondary gradient drift waves $V_{d s}$ [see Sudan et al. (1973) and Sect. 1] and assuming $v_{i}=2.5 \times 10^{3} \mathrm{~s}^{-1}, \quad v_{e}=4 \times 10^{4} \mathrm{~s}^{-1}, \quad \Omega_{i}=180 \mathrm{~s}^{-1}$ and $\Omega_{e}=10^{7} \mathrm{~s}^{-1}$ [typical values at $110-\mathrm{km}$ altitude (Fejer et al., 1984)], gives $V_{d s} \approx 13.2 \cdot \boldsymbol{V}_{\boldsymbol{E} \times \boldsymbol{B}}\left(\delta n / n_{0}\right)$. Then, for the four examples illustrated in Fig. 5, with values of $V_{d s} / \boldsymbol{V}_{\boldsymbol{E} \times \boldsymbol{B}}$ in the range $0.3-0.75, \delta n / n_{0}$ has values between $2 \%$ and $6 \%$. Another interpretation of the discrepancy between the unsaturated E-region irregularity phase velocity and $\boldsymbol{V}_{\boldsymbol{E} \times \boldsymbol{B}}$ is that high E-region turbulence (especially under the high electric field conditions observed) allows channel 1 backscatter to be observed from a non-orthogonal geometry, i.e. high aspect angles. In this situation, both the unsaturated (type II) and saturated (type I) E-region velocities will be depressed below their expected values. Such a conclusion is consistent with the VHF observations of Kustov et al. (1994).

The determination of $\theta$ is not considered accurate enough to verify that saturation of the channel 1 velocity occurs exactly for $\boldsymbol{V}_{\boldsymbol{E} \times \boldsymbol{B}} \cos \theta>C_{S}(1+\Psi)$. However, it is noted that in the high $\boldsymbol{V}_{\boldsymbol{E} \times \boldsymbol{B}}$ examples (Fig. 5a, b) saturation occurs near the left of the field of view where $\theta$ is high, and in the low $\boldsymbol{V}_{\boldsymbol{E} \times \boldsymbol{B}}$ examples (Fig. 5c, d) 
saturation occurs near the right of the field of view where $\theta$ is lower, consistent with such a behaviour.

In summary, the backscatter feature observed appears consistent with channel 1 and channel 2 backscatter originating in the $\mathrm{E}$ region and $\mathrm{F}$ region (or upper $\mathrm{E}$ region), respectively. In this case, the channel 2 velocities are the line-of-sight component of the plasma drift speed, $\boldsymbol{V}_{\boldsymbol{E} \times \boldsymbol{B}}$. The channel 1 velocities are, then, an underestimate of the line-of-sight component of the plasma drift speed (due to the secondary nature of the gradient drift waves or the non-zero aspect angle of the observations) in the unsaturated velocity regime, and the ion-acoustic speed in the saturated regime. The schematic presented in Fig. 3 summarises the regions of backscatter that are observed, the backscatter characteristics in the two ionospheric backscatter channels (line-of-sight velocity and spectral width) and an identification of the spectral type or instability mechanism thought to be operating in each region.

\subsection{Comparison of E-region and F-region backscatter characteristics}

On 24 November 1995, the two channel backscatter pattern was observed for approximately 90 min between 1915 and 2045 UT. Figure 7 illustrates time-series of the backscatter channel characteristics: the mean backscatter power along each channel (panel a); the line-of-sight velocity at which the channel 1 flow saturates, $V_{\text {sat }}$, and the estimated plasma drift velocity, $\boldsymbol{V}_{\boldsymbol{E} \times \boldsymbol{B}}$, of the channel 2 backscatter (panel b); and the magnetic latitude of the channel 1 backscatter region (panel c). $\boldsymbol{V}_{\boldsymbol{E} \times \boldsymbol{B}}$ is estimated from the mean of $V_{l o s} / \cos \theta_{\text {model }}$ along channel 2 . Between 1930 and 2045 UT the channel 1 backscatter region progresses equatorwards by $1.5^{\circ}$ of latitude. This motion is consistent with the expected equatorwards motion of the auroral oval with magnetic local time.

After 1915 UT the mean backscatter power along each channel increases. The power reaches a maximum at approximately 2015 and 2030 UT in the case of channel 1 and channel 2, respectively; thereafter the power decreases. The mean powers along the two channels do not vary exactly in step, though such differences are probably due to variations in the crosssection of backscatter determined by the propagation and the orthogonality condition. In general, however, there is a broad agreement between the variation in the two channels, though with a mean difference in power between channels 1 and 2 of approximately $5 \mathrm{~dB}$.

Between 1915 and 1955 UT there is a general increase in $\boldsymbol{V}_{\boldsymbol{E} \times \boldsymbol{B}}$ as indicated by the channel 2 backscatter, from 700 to $1300 \mathrm{~m} \mathrm{~s}^{-1}$. This is accompanied, between 1930 and $1955 \mathrm{UT}$, by an increase in $V_{\text {sat }}$ from 350 to $650 \mathrm{~m} \mathrm{~s}^{-1}$. A decrease in $\boldsymbol{V}_{\boldsymbol{E} \times \boldsymbol{B}}$, from 1200 to $900 \mathrm{~m} \mathrm{~s}^{-1}$ between 2000 and 2015 UT is also accompanied by a corresponding decrease in $V_{\text {sat }}$ from 600 to $350 \mathrm{~m} \mathrm{~s}^{-1}$. A short-lived increase in $\boldsymbol{V}_{\boldsymbol{E} \times \boldsymbol{B}}$ after 2015 UT once more raises $V_{\text {sat }}$ to $650 \mathrm{~m} \mathrm{~s}^{-1}$, after which $V_{\text {sat }}$ decreases slowly to $500 \mathrm{~m} \mathrm{~s}^{-1}$ by 2045 UT. Despite the good correlation between $\boldsymbol{V}_{\boldsymbol{E} \times \boldsymbol{B}}$ and $V_{\text {sat }}$, a final short-lived increase in

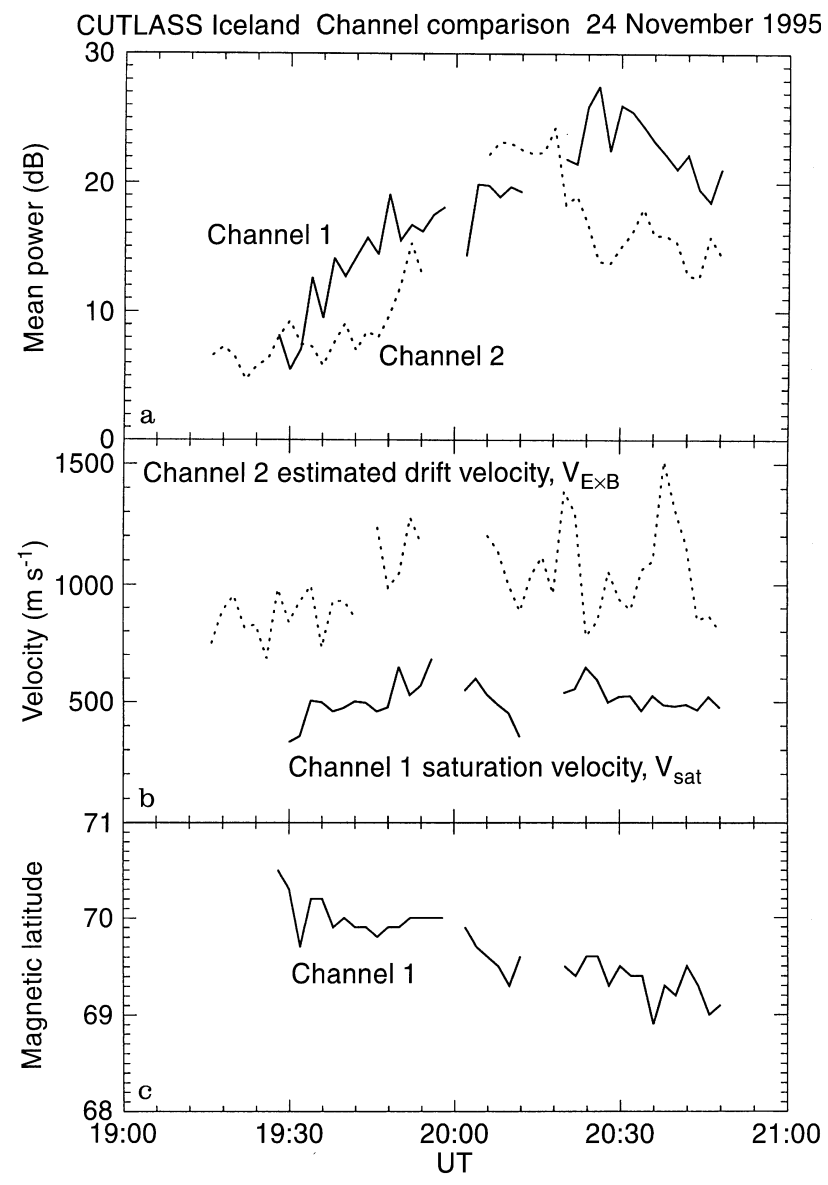

Fig. 7a-c. A comparison of time-series of backscatter characteristics from channels 1 (solid lines) and 2 (dotted lines) between 1915 and 2045 UT, 24 November 1995. a Mean backscatter power along each channel. b Estimated channel 2 plasma drift velocity, $\boldsymbol{V}_{\boldsymbol{E} \times \boldsymbol{B}}$, and the saturation velocity of channel $1, V_{\text {sat }}$. c The geomagnetic latitude of channel 1

$\boldsymbol{V}_{\boldsymbol{E} \times \boldsymbol{B}}$ at 2035 UT appears not to produce a corresponding increase in $V_{\text {sat }}$. If $V_{\text {sat }}$ is interpreted as the limiting velocity of type-I Doppler spectra, i.e. the ion-acoustic speed $C_{S}$ (see Sect. 4.3), then the general correspondence between the plasma drift speed and the ion-acoustic speed supports theories of E-region heating by large electric fields (e.g. Robinson, 1986). The cross-correlation between $\boldsymbol{V}_{\boldsymbol{E} \times \boldsymbol{B}}$ and $V_{\text {sat }}$ between 1915 and $2030 \mathrm{UT}$ (the interval during which correlation is best) maximises at 0.6 , with a time-lag between $\boldsymbol{V}_{\boldsymbol{E} \times \boldsymbol{B}}$ and $V_{\text {sat }}$ of $4 \mathrm{~min}$ (two radar scans). A scatter plot of $V_{\text {sat }}$ as a function of $\boldsymbol{V}_{\boldsymbol{E} \times \boldsymbol{B}}$ for this interval (with the 4-min time-lag) is illustrated in Fig. 8. Also indicated is a theoretical relationship between $C_{S}$ and $\boldsymbol{V}_{\boldsymbol{E} \times \boldsymbol{B}}$ for an altitude of $110 \mathrm{~km}$. This relationship is based on the approximately linear increase in electron temperature with electron drift speed, from $T_{e} \approx 300 \mathrm{~K}$ at $\boldsymbol{V}_{\boldsymbol{E} \times \boldsymbol{B}}=600 \mathrm{~m} \mathrm{~s}^{-1}$ to $T_{e} \approx 1400 \mathrm{~K}$ at $\boldsymbol{V}_{\boldsymbol{E} \times \boldsymbol{B}}=1400 \mathrm{~m} \mathrm{~s}^{-1}$ (Robinson, 1986) (see also the discussion of enhanced E-region temperatures in Sect. 4.3). Assuming an ambient value of $C_{S}=400 \mathrm{~m} \mathrm{~s}^{-1}$ and that the ion temperature remains unchanged $\left(T_{i}=300 \mathrm{~K}\right)$ with increasing $\boldsymbol{V}_{\boldsymbol{E} \times \boldsymbol{B}}$, relatively 


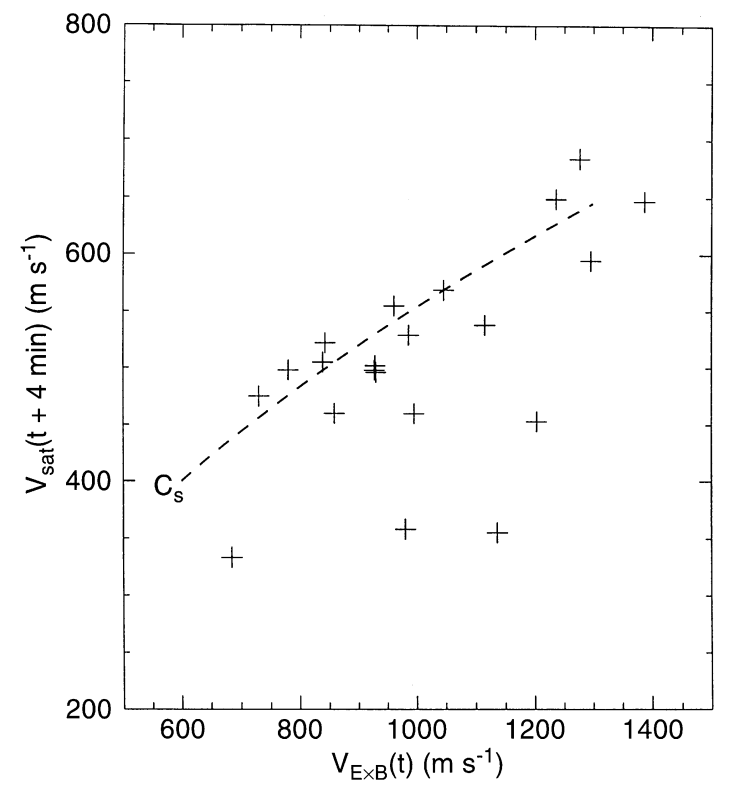

Fig. 8. A comparison of $V_{\text {sat }}$ and the estimated value of $V_{E \times B}$ for the interval 1915 to 2030 UT, 24 November 1995. Also indicated is a theoretical relationship between $V_{E \times B}$ and the ion-acoustic speed, $C_{s}$ (dashed line)

good agreement is found between the observations and the theoretical prediction.

It is also possible that these data provide evidence of a plasma drift speed dependence of the backscatter cross-section. The general increase in backscatter power with time (see above) appears to be modulated by the variation in velocity measured along each channel; most obviously the backscatter power of channel 1 increases as $V_{\text {sat }}$ increases between 1930 and $2000 \mathrm{UT}$, and decreases as $V_{\text {sat }}$ decreases between 2020 and 2045 UT. A similar, though less clear trend occurs for the velocity and backscatter power of channel 2. An exact correspondence between velocity and backscatter power can not be expected due to other, unmeasured, geophysical parameters which could affect their interdependence, viz. the backscatter volume size and the backscatter altitude, and the electron density and gradients in the electron density. However, such an increase in backscatter crosssection with increasing plasma drift velocity has previously been noted in VHF radar backscatter observations in the $V_{d}$ velocity range 200 to $700 \mathrm{~m} \mathrm{~s}^{-1}$ (Shand et al., 1996, and references therein).

\subsection{Propagation to the scatter volume}

The electrojet region in which the backscatter of the present study is observed is co-located with the evening diffuse auroral zone. Precipitation in this diffuse auroral zone produces enhanced electron densities at E-region altitudes (e.g. Whalen, 1983) and, as a consequence, the characteristically high conductivities of the electrojet. That enhanced E-region electron densities are associated with the channel 1 backscatter region is indicated by the presence of the ground backscatter region in the observations (see Sect. 3). This ground backscatter is located at approximately twice the ground range of the channel 1 ionospheric backscatter, i.e. channel 1 appears near the reflection point of the radar beam. This is not entirely surprising, as for scattering to occur the radarwave vector $\boldsymbol{k}_{r}$ must be orthogonal to the close-tovertical magnetic field, which means that sufficient ionospheric refraction is present to bring $\boldsymbol{k}_{r}$ nearly horizontal and hence close to reflection. For reflection, the aurorally enhanced plasma frequency, $f_{o} E_{a}\left(\propto n_{0}^{2}\right)$, must satisfy the condition

$f_{o} E_{a} \cdot \sec \varphi \geq f_{r}$

where $f_{r}$ is the radar operating frequency and $\varphi$ is the angle of incidence of the radio wave on the ionosphere. For a curved-earth and straight-line propagation (valid for thin-layered E-region propagation), the reflection altitude $h$, elevation angle $\Delta$, the angle of incidence on the ionosphere $\varphi$ and the ground range $D$ of ground backscatter propagation are related by

$\tan (\beta+\Delta)=\cot \varphi=\left(h / R_{e}-\cos \beta+1\right) / \sin \beta$,

$\beta=D / 2 R_{e}$,

where $R_{e}$ is the radius of the earth. Near the left of the field of view, the ground backscatter has a range of approximately $800 \mathrm{~km}$; assuming $h=110 \mathrm{~km}$, then $\Delta \approx 15^{\circ}$, which is consistent with the interferometric observations (not shown), and $\varphi \approx 70^{\circ}$. The minimum plasma frequency of the aurorally enhanced $\mathrm{E}$ region can then be found, with $f_{r}=10 \mathrm{MHz}$, to be $f_{o} E_{a} \approx 3 \mathrm{MHz}$, corresponding to an electron density of approximately $1.1 \times 10^{11} \mathrm{~m}^{-3}$. The furthest range at which ionospheric backscatter can be observed by a single-hop E-region propagation mode can be determined by setting $\Delta=0^{\circ}$ to be approximately $1200 \mathrm{~km}$, corresponding to range gate 22; again this is consistent with the observations.

The backscatter spectra of channel 2 suggest a higher-altitude scattering volume than that of channel 1 (see Sect. 4.3). Figure 9 indicates two possible scenarios in which high-altitude scatter can be observed by the radar [ray-traces of a similar nature have been presented in Villain et al. (1985)]. In the first situation (labelled in the figure as CHANNEL 2a), the backscatter has an elevation angle lower than that of channel 1 and the scatter must occur at relatively low altitudes, between 130 and $170 \mathrm{~km}$, the upper E region. In the second case (CHANNEL 2b), the backscatter elevation angle is greater than that of channel 1 and scatter originates at higher altitudes, or over a range of altitudes (approximately $150-300 \mathrm{~km}$ ), essentially from the $\mathrm{F}$ region. In the CHANNEL $2 \mathrm{~b}$ case, there are further repercussions for the data interpretation. The range from which backscatter originates is determined from the group path delay of the returned radar signal. This is not a true measure of the ground range to the scatter volume, but of the radio-wave group path length (slant range). The slant range to a point in the $F$ region at a particular ground range is greater than the slant range to the same ground range at E-region altitudes. In this case it is possible that backscatter channels 1 and 2 are nearly co- 


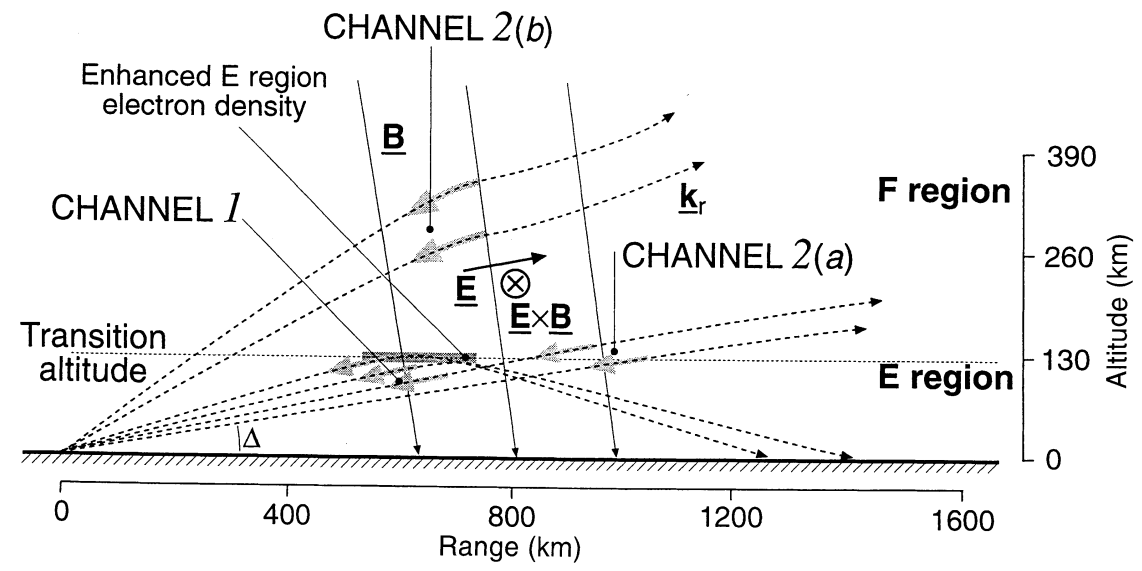

Fig. 9. A schematic diagram illustrating the propagation mode for the channel 1 backscatter region and the ground backscatter region, and two possible propagation modes for the channel 2 backscatter region located in range (or even magnetically conjugate), but are mapped to different radar ranges by the difference in their scattering altitude. Such an interpretation, however, requires a significant F-region electron density, sufficient to refract the radio wave to orthogonality with the magnetic field. A similar propagation analysis to that above can be applied to the channel 2 backscatter, assuming the CHANNEL $2 \mathrm{~b}$ case of Fig. 9. This indicates that scatter from a range of altitudes between 300 and $500 \mathrm{~km}\left(\Delta \approx 20^{\circ}\right.$ to $\left.35^{\circ}\right)$ requires $f_{o} F 2 \gtrsim$ 4.5-6.5 MHz. Such values are much higher than the ambient winter night-time F-region plasma frequency at the present phase of the solar cycle, though they are typical at solar maximum (see Milan et al., 1997b). There is evidence, however, that F-region electron densities of this magnitude are regularly produced by soft precipitation in the auroral zone (e.g. Kelley et al., 1982). It must also be noted that as ground backscatter is rarely associated with the channel 2 ionospheric backscatter, the radio wave does not have to be fully reflected by the ionosphere, only refracted to orthogonality with the magnetic field (with a dip angle of approximately $80^{\circ}$ ). In this case lower electron densities are necessary than the preceding analysis suggests.

In general, however, the elevation angle measurements made by the radar would suggest that the channel 2 backscatter usually has lower elevation angle than the channel 1 backscatter, supporting the CHANNEL 2a case, though the observations are highly ambiguous. Caution must be taken in interpreting the channel 2 elevation angles, due to the multipeaked nature of the backscatter spectra (see Fig. 6a). Multipeaked spectra suggest that backscatter originates from a range of altitudes within a single range cell (especially as some high-altitude spectra contain a peak corresponding to the E-region velocity, see Sect. 4.2), negating the interferometric assumption that the return signals have plane wavefronts. In this case the elevation angle measurements are unreliable.

\section{Summary}

A distinctive and recurrent $(60 \%$ of nights in November to January) backscatter feature is observed in the eastward auroral electrojet region by the CUTLASS Iceland coherent HF radar. This feature comprises two parallel, approximately zonally aligned regions of ionospheric backscatter, termed backscatter channels, with flow-angle-dependent velocities consistent with westward zonal plasma flow. At approximately twice the ground range of the nearer backscatter channel (channel 1) is a region of ground backscatter, indicating that the channel 1 ionospheric backscatter is associated with a region of enhanced E-region electron density, a feature of the high-conductivity auroral electrojets. The Doppler velocity of backscatter from channel 1 appears to be limited to the local ion-acoustic speed, $C_{S}$. Channel 1 backscatter with Doppler velocities near $C_{S}$ has narrow Doppler spectra $\left(\Delta V<100 \mathrm{~m} \mathrm{~s}^{-1}\right)$ compared with the width of backscatter spectra with lower velocities $\left(\Delta V \approx 300 \mathrm{~m} \mathrm{~s}^{-1}\right)$. The lower velocity and velocitylimited backscatter are interpreted as type-II and type-I E-region Doppler spectra, respectively. The backscatter of channel 2 is not velocity limited and has broader spectra which are often multipeaked $\left(\Delta V>300 \mathrm{~m} \mathrm{~s}^{-1}\right)$. This backscatter is attributed to instability mechanisms operating in the upper $\mathrm{E}$ region or $\mathrm{F}$ region, giving accurate line-of-sight estimates of the plasma drift speed, $\boldsymbol{V}_{\boldsymbol{E} \times \boldsymbol{B}}$.

A comparison of time-series of backscatter characteristics, such as backscatter power and Doppler velocity, from the two channels suggests that the local ionacoustic speed in the $\mathrm{E}$ region is modulated by the imposed electric field, as inferred from the F-region plasma flow. Also, there appears to be some positive correlation between backscatter power, related to the backscatter cross-section, and the Doppler velocity of the backscatter spectra.

Two propagation possibilities exist for the generation of E-region backscatter and upper-E or F-region backscatter in the pattern observed. In both cases, the channel 1 backscatter is generated near 110-km altitude in a region of aurorally enhanced E-region electron density, which provides sufficient refraction to reflect the radar wave and generate ground backscatter at twice the range. The higher-altitude backscatter can be observed by high-elevation angle rays being refracted to orthogonality with the magnetic field within the $\mathrm{F}$ region, or by low-elevation angle rays achieving or- 
thogonality in the upper $\mathrm{E}$ region or lower $\mathrm{F}$ region. Elevation angle measurements appear to support the latter possibility in most of the cases where this backscatter feature is observed, though these observations are highly ambiguous. As channels 1 and 2 are narrow bands in latitude, occur simultaneously, are separated by only a few range gates and appear to react to the same applied electric field, the most reasonable interpretation is that they are the E- and F-region signatures of the same magnetospheric/ionospheric phenomenon, i.e. that they are magnetically conjugate (CHANNEL 2b). If this is the case, then the backscatter feature described represents the ionospheric footprint of an important magnetospheric process or boundary, involving intense electric fields (sometimes in excess of $150 \mathrm{mV} \mathrm{m}^{-1}$, plasma drift velocities greater than $3 \mathrm{~km} \mathrm{~s}^{-1}$ ) in an azimuthally extended region no wider than $150 \mathrm{~km}$ or $1.5^{\circ}$ of latitude. Unfortunately, an investigation of the magnetospheric source of this feature is outside the scope of the present paper, but will form the basis of future work.

Alternatively, if the CHANNEL 2a propagation mode occurs, then it is probable that the orthogonality condition can be achieved at altitudes near $130 \mathrm{~km}$, i.e. in the transition region between the $\boldsymbol{V}_{\mathrm{d}} \cong \boldsymbol{E} \times \boldsymbol{B} / B^{2}$ and $\boldsymbol{V}_{\mathrm{d}} \cong-\left(v_{i} / \Omega_{i}\right) \boldsymbol{E} / B$ regimes, at ranges between channels 1 and 2. This allows the prospect of investigating the behaviour of irregularities in this interesting region, especially with a modified radar scan mode in which the gate length is reduced from the $45 \mathrm{~km}$ of the present study to, say, $15 \mathrm{~km}$.

Studies such as that presented in this paper allow simultaneous measurements of the backscatter spectra from irregularities in both the $\mathrm{E}$ region and at higher altitudes. This comparison of the relatively well understood E-region backscatter with backscatter from the relatively poorly studied F-region irregularities helps to illuminate both phenomena. In future, modified scan modes to improve temporal and spatial resolutions will be undertaken to investigate in detail these two different regimes. In particular, it is necessary to deduce the altitude of the backscatter forming channel 2. Evidence for the existence of similar features in the westward electrojet will also be sought.

Acknowledgements. CUTLASS is supported by PPARC, the Swedish Institute for Space Physics, Uppsala, and the Finnish Meteorological Institute. SEM is supported on PPARC grant no. GR/L00865.

Topical Editor D. Alcaydé thanks M. Uspensky and G. Sofko for their help in evaluating this paper.

\section{References}

Baker, K. B., and S. Wing, A new magnetic coordinate system for conjugate studies at high latitudes, J. Geophys. Res., 94, 9139, 1989.

Buneman, O., Excitation of field-aligned sound waves by electron streams, Phys. Rev. Lett., 10, 285, 1963.
Cahill, L. J., R. A. Greenwald, and E. Nielsen, Auroral radar and rocket double probe observations of electric field across the Harang discontinuity, Geophys. Res. Lett., 5, 687, 1978.

Chaturvedi, P. K., J. D. Huba, S. L. Ossakow, P. Saryanarayana, and J. A. Fedder, Parallel current effects on two-stream electrojet plasma instabilities, J. Geophys. Res., 92, 8700, 1987.

Davies, J. A., and T. R. Robinson, Heating of the high-latitude ionospheric plasma by electric fields, Adv. Space Res., in press, 1997.

Ecklund, W. L., B. B. Balsley, and D. A. Carter, A preliminary comparison of F-region plasma drifts and E-region irregularity drifts in the auroral zone, J. Geophys. Res., 82, 195, 1977.

Farley, D. T., A plasma instability resulting in field-aligned irregularities in the ionosphere, J. Geophys. Res., 63, 6083, 1963.

Fejer, B. G., and M. C. Kelley, Ionospheric irregularities, Rev. Geophys. Space Phys., 18, 401, 1980.

Fejer, B. G., and J. F. Providakes, High-latitude E-region irregularities: new results, Phys. Scr., T18, 167, 1987.

Fejer, B. G., D. T. Farley, B. B. Balsley, and R. F. Woodman, Vertical structure of the VHF backscattering region in the equatorial electrojet and the gradient drift instability, $J$. Geophys. Res., 80, 1313, 1975.

Fejer, B. G., J. F. Providakes, and D. T. Farley, Theory of plasma waves in the auroral E region, J. Geophys. Res., 89, 7487, 1984.

Feldstein, Y. I., and G. V. Starkov, Dynamics of auroral belt and polar geomagnetic disturbances, Planet. Space Sci., 15, 209, 1967.

Greenwald, R. A., W. L. Ecklund, and B. B. Balsley, Radar observations of auroral electrojet currents, J. Geophys. Res., 78, 8193, 1973.

Greenwald, R. A., W. L. Ecklund, and B. B. Balsley, Auroral currents, irregularities, and luminosity, J. Geophys. Res., 80, $3642,1975$.

Greenwald, R. A., W. Weiss, E. Nielsen, and N. R. Thomson, STARE: a new radar auroral backscatter experiment in northern Scandinavia, Radio Sci., 13, 1021, 1978.

Greenwald, R. A., K. B. Baker, J. R. Dudeney, M. Pinnock, T. B. Jones, E. C. Thomas, J.-P. Villain, J.-C. Cerisier, C. Senior, C. Hanuise, R. D. Hunsucker, G. Sofko, J. Koehler, E. Nielsen, R. Pellinen, A. D. M. Walker, N. Sato, and H. Yamagishi, DARN/ SuperDARN: A global view of the dynamics of high-latitude convection, Space Sci. Rev., 71, 761, 1995.

Haldoupis, C., A review on radio studies of auroral E-region ionospheric irregularities, Ann. Geophysicae, 7, 239, 1989.

Hall G. E., J. W. Macdougall, J. P. St-Maurice, D. R. Moorcroft, and A. H. Manson, Super Dual Auroral Radar Network observations of meteor echoes, J. Geophys. Res. 102, 1460314614, 1997.

Hanuise, C., J. P. Villain, D. Gresillon, B. Cabrit, R. A. Greenwald, and K. B. Baker, Interpretation of HF radar ionospheric Doppler spectra by collective wave scattering theory, Ann. Geophysicae, 11, 29, 1993.

Holzworth, R. H., and C.-I. Meng, Mathematical representation of the auroral oval, Geophys. Res. Lett., 2, 377, 1975.

Kelley, M. C., J. F. Vickery, C. W. Carlson, and R. Torbert, On the origin and spatial extent of high-latitude F-region irregularities, J. Geophys. Res., 87, 4469, 1982.

Knox, F. B., A contribution to the theory of the production of fieldaligned ionization irregularities in the equatorial electrojet, $J$. Atmos. Terr. Phys., 26, 239, 1964.

Kustov, A. V., M. V. U. spensky, G. J. Sofko, J. A. Koehler, and J. $\mathbf{M u}$, Aspect angle dependence of the radar aurora Doppler velocity, J. Geophys. Res., 99, 2131, 1994.

Maeda, K., T. Tsuda, and H. Maeda, Theoretical interpretation of the equatorial sporadic E-layers, Phys. Rev. Lett., 11, 406, 1963.

Milan, S. E., T. B. Jones, T. R. Robinson, E. C. Thomas, and T. K. Yeoman, Interferometer evidence for the observation of ground backscatter from behind the CUTLASS radars, Ann. Geophysicae, 15, 29, 1997a. 
Milan, S. E., T. K. Yeoman, M. Lester, E. C. Thomas, and T. B. Jones, Initial backscatter occurrence statistics from the CUTLASS HF radars, Ann. Geophysicae, 15, 703, 1997b.

Nielsen, E., and K. Schlegel, A first comparison of STARE and EISCAT eletron drift velocity measurements, J. Geophys. Res., 90, 3495, 1983.

Nielsen, E., W. Güttler, E. C. Thomas, C. P. Stewart, T. B. Jones, and A. Hedberg, A new radar auroral backscatter experiment, Nature, 304, 712, 1983.

Ossakow, S. L., and P. K. Chaturvedi, Current convective instability in the diffuse aurora, Geophys. Res. Lett., 6, 323, 1979.

Primdahl, F., and A. Bahnsen, Auroral E-region diagnosis of nonlinearly stabilized plasma waves, Ann. Geophysicae, 3, 57, 1985.

Providakes, J. F., D. T. Farley, W. E. Swartz, and D. Riggin, Plasma irregularities associated with morning discrete auroral arcs. Radar interferometry observations and theory, J. Geophys. Res., 90, 7513, 1985.

Robinson, T. R., Towards a self-consistent non-linear theory of radar auroral backscatter, J. Atmos. Terr. Phys., 48, 417, 1986.

Robinson, T. R., Simulation of convection flow estimation errors in VHF bistatic auroral radar systems, Ann. Geophysicae, 11, 1033, 1993.

Rogister, A., N. D'Angelo, Type 2 irregularities in the equatorial electrojet, J. Geophys. Res., 75, 3879, 1970.

Ruohoniemi, J. M., R. A. Greenwald, K. B. Baker, J. P. Villain, and M. A. McCready, Drift motions of small-scale irregularities in the high-latitude $\mathrm{F}$ region: an experimental comparison with plasma drift motions, J. Geophys. Res., 92, 4553, 1987.
Shand, B. A., M. Lester, and T. K. Yeoman, The relationship between VHF radar auroral backscatter amplitude and Doppler velocity: a statistical study, Ann. Geophysicae, 14, 803, 1996.

Shand, B. A., S. E. Milan, T. K. Yeoman, P. J. Chapman, D. M. Wright, T. B. Jones, and L. T. Pedersen, CUTLASS HF radar observations of the Odden ice tongue, Ann. Geophysicae, in press, 1997.

Sudan, R. N., Unified theory of Type I and Type II irregularities in the equatorial electrojet, J. Geophys. Res., 88, 4853, 1983.

Sudan, R. N., J. Akinrimisi, and D. T. Farley, Generation of smallscale irregularities in the equatorial electrojet, J. Geophys. Res., 78, 240, 1973.

Tsunoda, R. T., R. I. Presnell, Y. Kamide, and S.-I. Akasofu, Relationship of radar aurora, visual aurora, and auroral electrojects in the evening sector, J. Geophys. Res., 81, 6005, 1976.

Villain, J. P., G. Caudal, and C. Hanuise, A SAFARI-EISCAT comparison between the velocity of F-region small-scale irregularities and the ion-drift, J. Geophys. Res., 90, 8433, 1985.

Villain, J. P., R. A. Greenwald, K. B. Baker, and J. M. Ruohoniemi, HF radar observations of E-region plasma irregularities produced by oblique electron streaming, J. Geophys. Res., 92, 12327, 1987.

Whalen, J. A., A quantitative description of the spatial distribution and dynamics of the energy flux in the continuous aurora, $J$. Geophys. Res., 88, 7155, 1983. 